\title{
Internet in the Street Project: Helping the Extremely Poor to Enter the Information Society
}

\author{
Corinne Chevrot, Emmanuelle Comtat, Gwenaël Navarette, Bruno Oudet, \\ Jean-Pierre Pinet \\ ATD Quart Monde France, \\ jeanpierre.pinet@atd-quartmonde.org, http://www.atd-quartmonde.o \\ Leibniz Laboratory, University of Grenoble, France, \\ bruno.oudet@imag.fr, http://www-leibniz.imag.fr
}

\begin{abstract}
The most common measures so far to reduce the digital divide has been the development of telecentres (Internet public access points) that provide Internet access and specific training. However, the extremely poor very rarely enter the telecentres. In this paper, we propose a more specific approach suited to this population. We first describe the social-digital exclusion process facing the extremely poor, its inputs, its outputs, and our approach to help the poor to start to integrate the information society. We then present stories collected during our field actions in our Internet in the street project. We conclude by presenting what we have learnt so far.
\end{abstract}

Keywords: digital divide, extremely poor

\section{Introduction}

It is now obvious that what we call the information society will have a growing impact on communication, education, knowledge acquisition and the development of social relations. It is thus a matter of respect of human rights to work so that we leave no one behind, especially the persons who may need it most. Among those experiencing exclusion are illiterate populations, people with disabilities, inhabitants in remote areas and the extremely poor. In the literature, the gap that exists between communities taking advantages of the information society and those excluded from it called the digital divide [1]. Numerous actions have been proposed to reduce the digital divide during the United Nations Word Summit on the Information Society in Geneva (2003) [2] and Tunis (2005) [3]. The Digital Divide Network [4] coordinated

Please use the following format when citing this chapter:

Chevrot, C., Comtat, E., Navarette, G., Oudet, B., Pinet, J.-P, 2006, in IFIP International Federation for Information Processing, Volume 223, Social Informatics: An Information Society for All? In Remembrance of Rob Kling, eds. Berleur, J., Numinen, M. I., Impagliazzo, J., (Boston: Springer), pp. 309-318. 
by Andy Carvin is the online forum where one can share experiences and knowledge on the subject.

In the digital divide debate, we can distinguish at least two schools of thought. One school embraces the working of the market forces to close progressively the digital divide; organizing and encouraging a true competition and providing training will do the job. For others, the digital divide is not an isolated symptom; it is just another expression of the social divides facing society. Fighting against the digital divide implies undertaking actions to reduce social exclusions. This second approach is the one retained by the eEurope Advisory Group in its July 2005 report [5].

The project presented in this paper is in line with this second approach. Our objective is the reduction of the digital divide for the extremely poor. These persons are in 'chronic poverty and lack of basic security'. They are also "Geographically segregated and socially isolated, they are cut off from the cultural, political and civil life of the country" [6]. We cannot reach the extremely poor via a top-down approach. It requires a collaborative approach that embraces the notion, "let us learn together what Internet can bring in your daily life'. While working with the extremely poor we cannot avoid basic questions. Why are we emphasizing the use of Internet for the very poor? Don't the poor have other priorities such as finding jobs, keeping their families together? In truth, the poor themselves must provide answers to these questions. "The best informed experts on poverty are the poor". [6]

We first describe what we call the social-digital exclusion process facing the extremely poor: its inputs (causes), its outputs (consequences) and our approach to help the poorest to start to take advantage of the Information Society. We then present the Internet in the street project and our approach before telling stories collected during our action in the field. We conclude by presenting what we have learnt so far.

\section{The Social-Digital Exclusion Process}

Table 1 lists the inputs and the outputs of the social-digital exclusion process.

Table 1. Inputs and outputs of the social-digital exclusion process

\begin{tabular}{ll}
\hline $\begin{array}{l}\text { INPUTS } \\
\text { Barriers to entry }\end{array}$ & $\begin{array}{l}\text { OUTPUTS } \\
\text { Participation to the IS }\end{array}$ \\
\hline $\begin{array}{l}\text { access to equipment } \\
\text { access to the net }\end{array}$ & $\begin{array}{l}\text { access to information } \\
\text { communication }\end{array}$ \\
know-how & $\begin{array}{l}\text { access to opportunities (employment, ) } \\
\text { access to knowledge (training...) }\end{array}$ \\
$\begin{array}{l}\text { fear of the unknown, of ICT's impact } \\
\text { lack of quality, culturally relevant content } \\
\begin{array}{l}\text { Motivation } \\
\text { feeling of exclusion } \\
\text { existing social networks }\end{array}\end{array}$ & $\begin{array}{l}\text { creation of relevant content } \\
\text { participation in the democratic process }\end{array}$ \\
\hline
\end{tabular}




\subsection{The Inputs}

Lack of access to equipment and to the net is of course a factor of exclusion of the Information Society. The world devotes much effort to reduce these two sources of exclusion. The computer + connectivity mix is however not sufficient. They are other major causes to the exclusion process. The lack of expertise to use a computer is one of them. Much work remains to simplify the computer interface, to make it more easily accessible and user friendly.

'I am not intelligent enough to use a computer' 'I am a hand worker, it is not for me' are reaction we often hear. This reaction concern more than just basic ICT literacy or general literacy, as well as not understanding ICT's relevance in improving their quality of life.

The lack of motivation is another important obstacle. The very poor families are often facing difficult situations. Their interest for using Internet such as discovering images from their homeland, sending messages can disappear suddenly when they face problems that take their full attention.

The feeling of exclusion - 'it's not for me' - is another major obstacle. The majority of the persons we are meeting in our project have a strong feeling that the 'outside world' is not accessible. One person told us that the only places outside their homes where they felt safe are the shopping centers because they are looked upon as potential customers and not as strangers. The feeling of exclusion has its own dynamic: it increases with the development of the Information Society. In the 1980's, a very poor person said to Father Joseph Wresinski, the founder of ATD Fourth World movement 'I don't know to read, but I think that it will be even worst with Informatics'. The very poor realized at that time that this was a new important challenge facing them, and they felt excluded from this new world. The very poor social links are generally limited to their families and to their immediate neighborhood. Compared to others, they have more difficulties to realize that the Internet can help to develop social relations. Migrants are an exception, though, because they often perceive the benefits of email and the web to keep contact with their homeland.

In our project, it is relatively easy to bypass the material obstacles, and we are relatively successful in providing the sufficient knowledge to use the computer. What is very time consuming is the required human investment. The socioeconomic situation of the poor has deteriorated for such a long time that the action team needs first to rebuild the trusted relationship between the people they meet and themselves. It takes even more time to reconcile the extremely poor with their social environment (schools, libraries, and administration), overcoming racism, social exclusion, and creating relationship.

We also realize that our effort can be easily interrupted or even destroyed. For example, the relations with a group of people living in mobile homes were interrupted because an expulsion decision from the living quarter was decided during the summer 2005 by the local administration. Extreme poverty and social exclusion are like waves that unceasingly come to erase the sand castle built on the beach. 


\subsection{The Process: Moving from 'Digital Exclusion' to 'Participant in the Knowledge Society'}

In the heart of the process are the commitments of persons from the civil society who are external to the world of extreme poverty. By the word commitment, we point at these voluntary acts of working with very poor populations despite all the many challenges associated with working in overcoming these situations.

Nevertheless, the commitments are not sufficient. We should create situations where the social links are restored, where the people we met have the possibility of meeting others with whom, thereafter, they will be able to interact over the Internet. For example, a person once active in our project in the Paris suburbs area left for Algeria. She started email exchanges with the poor communities she had encountered in Paris. Another example is a person who, touched by the situation of prisoners in Ivory Coast, started to send postcards to a volunteer working in that prison. This volunteer was later assigned to Bangui, in Central Africa, and the dialogue quite naturally continued with email.

A third aspect is the necessity of implying the very poor in the creation of robust, relevant content for the web. One of the obvious reasons for which a certain number of people do not use information and communication technologies is that they do not find content that interesting or relevant to them. Helping people to develop content to the Net contributes to fighting digital exclusion.

\subsection{The Outputs}

The outputs appear in Column 2 of Table1. We need to emphasize that these persons are facing many difficulties that are far away from the digital world. The Internet is not the sole solution to their problems. We thus have always to look for digital outputs that can be of interest to them.

One of the objectives currently put forward by UNESCO in its Community Multimedia Centers program [7] is to initiate changes that will increase the level of income of the community. This program stresses the potential economic impact on the poor communities, their access to their own rights and their cultural development. Nevertheless, does this approach have an impact on those who are excluded from their community?

We have always to remember that the inclusion into the information society is only one little contribution to the difficulties facing the very poor. It is a true challenge to develop a dynamic that can bring concrete benefits. For example, many Roma from Romania do not have the necessary documents to stay legally in France, despite the fact they will become European citizen in 2007 . Their situation as illegal immigrants prevents them to have access to employment, healthcare, and even to school for their children. Unfortunately, this is a matter of political decision making which is outside the Internet domain even if Internet can be used to draw public attention on these situations. 


\section{The 'Internet in the Street' Project}

In France as in other countries, many efforts are devoted to reduce the digital divide. They focus on providing computer and Internet access, as well as training. A recent report [8] on the public access point in the Ile de France region provides a good presentation on what is currently happening. A department within the French Ministry of Education is in charge of the follow-up of the public telecentres [9]. We can find a description on the ongoing research on the digital divide in [10].

Several initiatives were launched recently with objectives close to the ones of our project: in Paris, the telecentre in the Emmaüs NGO Agora [11], 'Le dire pour agir' web site of the Secours Populaire Français [12], 'paroles de rue', web site of the NGO 'aux captifs la liberation' [13] and 'Couleur Quartier' in Brest [14].

The 'Internet in the Street' project [15] was launched at the end of 2004. Its goal is to conduct research to study how the Internet can help to create or restore the socials links for very poor communities. We choose the 'Internet in the Street' appellation to refer to the library in the street, which is an on going ATD Fourth World project for many years. In addition, we wanted the project to be a continuation of 'computer in the street' projects that the ATD Fourth World carried out with children in the 1980s [16]. In our project, we focus on helping adults, who generally are not as receptive to technology as young people.

The research team in the field consists of three volunteers (name given to ATD Fourth World full time collaborators). Two researchers in Grenoble are in charge of the follow-up and of the links with the scientific world. We keep two web sites: one blog [17] and a web site open to various contributions and testimony [18]. We have weekly exchanges through a mailing list and we meet once a month in Paris. We hold in June and in October seminars with the team of the PSAUME project [19] that is studying how to reach the excluded persons in the Brest region.

The ATD volunteers have the same equipment: a computer with only one battery (access to electricity is still a problem), a card for multiple wireless accesses to the Internet (WIFI, GPRS, 3G, and EDGE), a color printer with battery, a digital camera.

Despite the title of our project, only one volunteer had spent a limited part of her time in the street with a computer to reach homeless persons. The action toward homeless takes place more easily 'under a roof' in places where they usually go by for a coffee, getting their postal mail. Two volunteers meet the very poor in their living quarters, mostly mobile homes or very low-rent apartments. All the volunteers have the same approach: they go to meet extremely poor people in their living places.

\subsection{The Approach: Collaborative Learning with the Very Poor}

It has been a long working tradition of ATD-Fourth World volunteers to learn in the field together with the very poor [20]. This approach of ethnographic nature observes and contributes to practices of everyday life. This contributes to a long immersion in the field and differs from the classical top-down research where the scientist puts forth assumptions and seeks to check them. In our project, we observe what the 
persons we meet consider as 'successful' actions; we then collect them and try to make sense of them [21].

\subsection{Collected Stories}

One of the main outputs of our project is the collection of stories written in our blog after our field work [17]. They are 'success stories' for people we meet: they express their way of finding a place in society. Based on these stories we shall provide in our final project report concrete suggestions for other NGO's willing to help the extremely poor persons to take advantage of the Information Society.

\section{Voice over Internet}

A volunteer tested voice communication by Internet with families in mobile homes using Skype. The objective was to speak to a person who visited their families last year. During the conversation a connected Romanian friend sought to speak to this volunteer. It was impressive for these families in the Val d'Oise (a remote suburb of Paris) to realize that they were able to speak with somebody living in Romania, only with this computer.

\section{Information on the floods back home}

From the very start of the project, Rrom families have shown great interest in obtaining news from their home country. At nearly each meeting, we look at newspapers online. Sometimes, we print an article that makes the tour of the camp. Since the beginning of the summer, a succession of floods had damaged Romania. They were all anxious for their families. This time, the newspaper posted a gallery of photographs on the floods in New Orleans. The person who was in front of the screen took much time to look at each photograph, asked the volunteer to translate the English legend. It was not simple curiosity; the expression was the glance of a person who knew the misfortune that strikes the poorest people. The Internet can reinforce people's compassion for others.

\section{Looking for a job}

A volunteer met in a community center a person living in the street. This person shared how invaluable Internet was in his search for jobs. He sent its Curriculum vitae, motivation letter by Internet to the e-mail address indicated on the job offers of the ANPE (the national agency in France in charge) web site, saving on post, train, and subway travel expenses. He noticed that companies quickly answer his mail whether it was negative or positive which is usually not the case when you contact the Company by postal mail. You also do not show them that you do not posses a permanent address, which is important for people combating homelessness. He found some short time jobs by this way.

\section{Obtaining ID papers using the Internet}

One person a volunteer have been meeting for months did not have his French national ID card, despite of the fact that he was born as a French citizen. He has been reluctant to contact the administration due to his others difficulties: living in a mobile home, isolated from the outside world. With the volunteer, they had already 
gone together to fulfill a few administrative procedures. He had gone to the town hall on several occasions, in vain, unable to get his new ID card for lack of the necessary papers. He had lost hope of obtaining it. They started our search on Internet and filled an electronic form for getting a copy of his birth certificate. He obtained it by postal mail within two days without having to pay for a stamp. It gave him the feeling that finally he will be able to reach his goal. He now has his ID card, which gives him motivation for applying to a driving license.

\section{Taking a picture and printing it: a simple application to develop social links}

In mid-September of 2005 , a volunteer visited the Rrom families. They have recently been working on taking pictures. However, this time, it was a veritable festival! Inside the mobile home, ten people were around the computer and the printer. We printed on A4 page a picture taken during our last meeting: it was almost 'magic' to them. Then, there was this 'old' digital camera, found somewhere, for which I had never succeeded in finding the driver. By chance with my flash reader, I was able to 'extract' and print the pictures. The pictures made the tour of the camps. The young person that returned them to me then had an idea: "I will send the camera to my mother who is still in my country. She will take photographs, and specially the one of my son whom I have not seen any more for two years. He was five years old when I left him. She will return the camera to me, and we will print them here."

\section{Side effects}

Even while paying attention, we do not always realize the type of change we are initiating. Recently, at the time of a meeting with other volunteers in the field, one of them told us: "You do not imagine what you initiated with your Internet. Mr. X (out of the employment world for a long time) gets up generally very late. As he knows that you are coming, he gets up earlier seeking an activity, a work to make him busy when you arrive". Within the framework of our cultural activities with children, it has been difficult to tackle the question of administrative papers with the parents, and especially with the men. With the help of our computer we carry to their homes, we can speak more easily about their papers.

These stories clearly validate the exclusion process presented in Table 1 . We are very far from a simple digital divide process. Providing computers, access, and basic training is not sufficient; we need to bring IT to the very poor at the point that is the closest both to their living quarters and to their places of employment. By doing so we fight against their feeling of exclusion, we help them to recover confidence, starting a dynamic process that could help them to better face their difficult and delicate situations.

\section{What Have We Learnt So Far?}

We provide below a first list of findings after one and half year of this experimental project.

- Even if they do not constitute major obstacles, we should not neglect common technical problems: batteries, wireless access to the Internet, maintenance of the 
machines, need for working under XP or equivalent (our $3 \mathrm{G}$ card recognizes only XP system). During several weeks the project was delayed (and is still) because one or the other component was deficient;

- The presence of a laptop computer facilitates contact with the people who live on the street. However, volunteers can intervene only after introduced by an already accepted and trusted person. It takes time and energy to make this acquaintance. The length of time to do so varies according to social backgrounds... In our case, the presence of the computer helps and some time shortens the time necessary to establish the contact.

- The computer brings in some way a 'neutral ground' that allows people with different history to begin exchanges. People living in the street feel the arrival of the ATD volunteer with a computer is a proof of confidence and of recognition. They also can discover the Internet, about which they have often heard on TV. The Internet is a good subject for introductions and launching discussions.

- We have always to be attentive to the concerns of the people we meet. People are often more demanding discussion than Internet use.

- People living in the street have very different sensibility and knowledge on the use of the computer due to their history. One can find in the street other persons who are able to help the ATD volunteer in the discovery and training of their companions.

- Once a relationship occurs, the dynamics can lead in unforeseeable directions. For example, as a by-product of our work we were able to convince NGO leaders who were very reluctant regarding our work. (They said it was a luxury that poor persons did not need!) Eventually, they became Internet pushers.

- The most popular applications: taking and printing pictures, finding news and writing to the family at home, help to obtain administrative papers, contributions to content on the web.

- We succeeded in creating relationships with libraries and NGOs, but we are also facing the lack of training of their staff to accept in their activities extremely poor people.

- After a time of discovery and learning on computer and Internet with extremely poor people, we continue our visits. Some ask us to participate to other activities. Because of the acquired trust, others ask us to undertake a more collective action.

\section{Conclusion}

Despite the overall growth of per capita incomes, the numbers of families facing chronic poverty in the wealthiest countries is increasing. To this population the development of the information society is an additional source of exclusion, as long as they too lack access and the skills to participate effectively. The fight against this new source of exclusion requires a lengthy, ongoing effort. In our project, we have been working for a short period of time (sixteen months in a very slow moving process) with a limited number of persons. Getting in contact with the poorest person, acquiring their trust, finding common ground of interest is a lengthy and delicate progress. Moreover, we faced a permanent obstacle: Individuals and families who are trying to deal with an accumulation of poverty-related problems can think of 
little else but meeting their basic needs [6]. We have to show concrete, real, and personal examples of what the Internet can bring to low-income communities. However, by doing so we are able to point to difficulties encountered by other excluded populations, including illiterate populations, the unemployed, senior citizens, and people with disabilities.

In the following months, we plan to complement our individual approach (one person, one family, a few persons in a camp) with a collective training closer to the one provided at telecentres. The group attending the training will be a combination of ATD Fourth World members and extremely poor persons keeping on the approach of collaborative learning. Our findings will complement the ones presented in this paper.

\section{References}

1. Digital divide, http://en.wikipedia.org/wiki/Digital_divide [3/29/2006]

2. WSIS Geneva Plan of Action, http://www.itu.int/wsis/docs/geneva/official/poa.html [3/29/2006]

3. WSIS Tunis Commitment and Tunis Agenda for the Information Society, http://www.itu.int/wsis/documents/index2.html [3/29/2006]

4. The Digital Divide Network, http://www.digitaldivide.net [3/29/2006]

5. eEurope Advisory Group, e-Inclusion: New challenges and policy recommendations, July 2005 ,

http://europa.eu.int/information_society/eeurope/2005/all_about/advisory_group/documen ts/index_en.htm [3/29/2006]

6. Joseph Wresinski, Chronic Poverty and Lack of Basic Security, Report of the Economic and Social Council of France, 1987. http://www.atdquartmonde.org/intern/fondam/Wres_JO87en.pdf [3/29/2006]

7. The UNESCO Community Media Centres, http://www.unesco.org/webworld/cmc $[3 / 29 / 2006]$

8. Etat des lieux du web public communal en 2005, ARTESI, http://www.artesi.artesiidf.com/public/anv/dossier.tpl?preview=1\&nolog\&id=10933 [3/29/2006]

9. Délégation aux usages de l'Internet, Qu'est ce qu'un espace public numérique?, http://delegation.Internet.gouv.fr/netpublic/index.htm [3/29/2006]

10. Alain Rallet (Editeur) La fracture numérique, Revue Réseaux , 22/127-128 (2005)

11. Bilan d'activités des 18 premiers mois du cyberespace Agora-Emmaus, paris, http:/www.a-brest.net/article 1530.html [3/29/2006]

12. 'Le dire pour agir' website, http://www.ledirepouragir.net [3/29/2006]

13. Paroles de rue website, http://www.captifs.asso.fr/parolesrue/index.html [3/29/2006]

14. 'Couleur quartier' website, http://www.couleurquartier.infini.fr/ [3/29/2006]

15. The Internet in the street project, http://reso.blogs.com/crealiens/Usesofinternet.rtf [3/29/2006]

16. Bruno Tardieu, High Technology and Low-Income Communities: Prospects for the positive use of advanced Information Technology, 1985 MIT seminar on High Technologies and Low income, 
http://www.mit.edu/afs/athena/org/s/sap/www/colloquium96/papers/12tardieu.html [3/29/2006]

17. The Internet in the street blog, http://reso.blogs.com/crealiens, [3/29/2006]

18. The Internet in the street expression space, http://www.carnet-expression.org/ [3/29/2006]

19. Le site du projet PSAUME 'Populations Socialement défavorisées : Analyse des Usages et des Moyens de les Étendre', http://www.psaume.infini.fr/ [3/29/2006]

20. «Le croisement des savoirs : quand le Quart Monde et l'Université pensent ensemble » Collection Des Livres contre la misère, Éditions de l'Atelier/Éditions Quart Monde, 1999

21. Jona Rosenfeld, Emergence from extreme poverty, editions Quart Monde, 1989, http://www.editionsquartmonde.org/live/detail_produit.php?parm_produit=149\&parm_cat $=98-\mathrm{NOUV} \&$ mots $=$ emergence $[3 / 17 / 2006]$ 